\title{
PENGARUH VARIASI DEBIT ALIRAN TERHADAP KARAKTERISTIK API PEMBAKARAN DIFUSI LPG DAN CNG
}

\author{
Influence of Flow Variation Fire Burning Characteristics Diffusion of LPG and CNG
}

\author{
Angga Dwinanda' ${ }^{1}$, Nely Ana Mufarida ${ }^{2}$, Asmar Finali ${ }^{3)}$ \\ ${ }^{1,2,3)}$ Jurusan Teknik Mesin, Fakultas Teknik, Universitas Muahammadyah Jember \\ Email: ${ }^{1)}$ angga.dwinanda@yahoo.com, ${ }^{2}$ nelyana_munfarida@yahoo.com, ${ }^{3)}$ pcfinali@gmail.com
}

\begin{abstract}
ABSTRAK
Proses pembakaran difusi banyak sekali diterapkan dalam kegiatan industri besar seperti penggunaan boiler pada pembangit listrik, ruang bakar pada pabrik-pabrik kimia maupun kegiatan rumah tangga. Namun untuk pemilihan penggunaan bahan bakar khususnya bahan bakar gas merupakan bagian yang terpenting untuk menekan biaya dan waktu. Penelitian ini melakukan pengamatan mengenai kualitas nyala api yang dihasilkan LPG dan CNG terhadap distribusi, tinggi api, dan warna api dengan membandingkan variasi debit aliran $0,204 \mathrm{~m}^{3} / \mathrm{jam}, 0,245 \mathrm{~m}^{3} / \mathrm{jam}, 0,285 \mathrm{~m}^{3} / \mathrm{jam}, 0,326 \mathrm{~m}^{3} / \mathrm{jam}, 0,367$ $\mathrm{m}^{3} / \mathrm{jam}$. Dari hasil pengujian distribusi nyala api tertinggi CNG dan LPG ada pada debit aliran bahan bakar tertinggi yaitu $0,367 \mathrm{~m}^{3} / \mathrm{jam}$ dan nyala api terendah ada pada debit aliran bahan bakar terendah sebesar $0,204 \mathrm{~m}^{3} / \mathrm{jam}$. tinggi nyala api tertinggi pada CNG lebih rendah dari pada nyala api terendah LPG. Persentase warna api biru CNG rata-rata tertinggi pada debit aliran 0,285 $\mathrm{m}^{3} / \mathrm{jam}$ sebesar 44,291 $\%$ dan LPG pada debit aliran $0,204 \mathrm{~m}^{3} / \mathrm{jam}$ sebesar $36,779 \%$. Pada suplai $0,245 \mathrm{~m}^{3} / \mathrm{jam} \mathrm{CNG}$ merupakan nyala api hijau terbaik sebesar $31,841 \%$ dan untuk LPG pada debit aliran $0,285 \mathrm{~m}^{3} / \mathrm{jam}$ dengan nilai $34,59 \%$. Persentase warna api merah terbesar berada pada debit aliran $0,204 \mathrm{~m}^{3} / \mathrm{jam}$ sebesar 30,205 \% dan LPG pada debit aliran 0,245 m³/jam sebesar 30,95\%.
\end{abstract}

Kata kunci : karakteristik nyala api, difusi, tinggi nyala api, warna nyala api, LPG, CNG, debit aliran.

\begin{abstract}
The diffusion combustion process is widely applied in large industrial activities such as the use of boiler in electricity builders, combustion chambers in chemical factories and household activities. However, for the selection of fuel use especially gas fuel is the most important part to reduce cost and time. This study conducted observation on the quality of the flame produced by LPG and CNG on the distribution, flame height, and color of fire by comparing the variation of flowrate $0.204 \mathrm{~m}^{3} / \mathrm{hour}, 0.245 \mathrm{~m}^{3} / \mathrm{hour}$, $0.285 \mathrm{~m}^{3} /$ hour, $0.326 \mathrm{~m}^{3} /$ hour, $0.367 \mathrm{~m}^{3}$ /hour. From the results of CNG and LPG highest flame distribution tests, the highest fuel flow rate is $0.367 \mathrm{~m}^{3} /$ hour and the lowest flame is at the lowest fuel flow rate of $0.204 \mathrm{~m}^{3} /$ hour. the highest flame height on CNG is lower than the lowest flame of LPG. The highest percentage of CNG blue flame color at flowrate $0.285 \mathrm{~m}^{3} /$ hour is $44.291 \%$ and LPG at flow rate $0.204 \mathrm{~m}^{3} /$ hour is $36.779 \%$. The supply of $0.245 \mathrm{~m}^{3} /$ hour CNG is the best green flame of $31.841 \%$ and for LPG the flowrate is $0.285 \mathrm{~m}^{3} /$ hour with a value of $34.59 \%$. The largest percentage of red flame color is at flowrate $0.204 \mathrm{~m}^{3} /$ hour by $30.205 \%$ and LPG at flowrate $0.245 \mathrm{~m}^{3} /$ hour is $30.95 \%$.
\end{abstract}

Keywords : flame characteristics, diffusion, flame height, flame color, LPG, CNG, flowrate.

\section{PENDAhuluan}

LPG adalah salah satu bahan bakar gas yang banyak dimanfaatkan dibidang industri maupun rumah tangga, sedangkan CNG sedikit dimanfaatkan oleh beberapa industri besar. Kedua gas tersebut untuk masyarakat masih belum banyak yang tau tentang karakteristik BBG tersebut. Angka RON LPG sebesar 98 namun nilai ini masih kalah dengan nilai 
CNG yang angka RON sebesar 120. Cadangan dalam negeri CNG melalui teknologi CMB mampu menyisakan 100 tahun, sedangkan LPG dengan side product dari CNG hanya mampu 50 tahun dan untuk harga $\mathrm{CNG}$ relative stabil tidak banyak dipengaruhi oleh harga internasional. Hal ini diupayakan bahwa untuk kebutuhan rumah tangga, transportasi dan industri, CNG dapat digunakan sebagai bahan bakar gas alternatif yang ikut membantu LPG dalam kebutuhan sehari-hari.

Liquid Petroleum Gas (LPG) merupakan gas yang terdiri dari beberapa senyawa hidrokarbon diantaranya senyawa utama tersebut adalah propana $\left(\mathrm{C}_{3} \mathrm{H}_{8}\right)$ dan Butana $\left(\mathrm{C}_{4} \mathrm{H}_{10}\right)$ sisanya kandungan gas lain, bahan bakar LPG terbuat dari destilasi minyak mentah (refining crude oil/ petroleum distillation) atau juga dihasilkan dari kondensasi gas alam.

Gas alam terkompresi atau yang dikenal dengan Compressed Natural Gas adalah suatu bahan bakar gas yang dapat menggantikan bahan bakar minyak karena dinilai memiliki emisi gas buang yang jauh lebih bersih atau ramah lingkungan. Di Indonesia pasokan bahan bakar minyak sudah mulai menipis, hal ini disebabkan karena sumber daya minyak mentah telah masuk masa kritis, namun ladang gas alam diperkirakan cukup memiliki pasokan yang besar yang dapat mencukupi di masa-masa mendatang sehingga pemerintah memberikan arahan untuk beralih ke bahan bakar gas.

Adapun penelitian ini bertujuan untuk mengetahui pengaruh debit aliran antara LPG dan CNG terhadap warna api dan tinggi api,

\section{TINJAUAN PUSTAKA}

Liquified petroleum gas atau LPG adalah sebuah gas hidrokarbon yang telah berbentuk cair setelah diberi tekanan, yang mana bertujuan untuk memudahkan dalam penyimpanan, pengangkutan, dan penanganan. LPG pada dasarnya terdiri atas propana $(\mathrm{C} 3 \mathrm{H} 8)$, butana $(\mathrm{C} 4 \mathrm{H} 10)$, atau campuran dari keduanya. LPG biasanya digunakan sebagai pengganti freon, aerosol, bahan pendingin (refrigerant/cooling agent), kosmetika, dan bahan bakar. Komponen utamanya LPG adalah gas propana dan butana, dengan komposisi kurang lebih 97\% dan selebihnya adalah zat pembau. Komposisi dasar campuran LPG produksi Pertamina mengandung 50 persen Propana dan 50 persen Butana, dilihat dari aspek komposisi yang terkandung dalam tabung LPG maupun aspek tekanan uap LPG, komposisi tersebut telah sesuai dengan ketentuan yang berlaku dan telah diperhitungkan sesuai nilai kalor yang diperlukan dalam proses memasak.

CNG Adalah produk Bahan Bakar Gas yang berasal dari gas bumi dengan unsur utamanya, Metana (C1) yang telah dimampatkan dan dipertahankan, serta disimpan pada bejana bertekanan khusus guna mempermudah pengangkutan dan penimbunan. Gas alam atau sering juga disebut gas bumi merupakan bahan bakar yang sangat sederhana. Sekitar $90 \%$ dari gas alam adalah metana $\left(\mathrm{CH}_{4}\right)$, yang hanya satu atom karbon dengan empat atom hidrogen melekat, dengan sisanya terdiri dari etana $\left(\mathrm{C}_{2} \mathrm{H}_{6}\right)$, propana $\left(\mathrm{C}_{3} \mathrm{H}_{8}\right)$, butana $\left(\mathrm{C}_{4} \mathrm{H}_{10}\right)$ dan komponen-komponen lain serta komponen pengotor seperti Air, $\mathrm{H}_{2} \mathrm{~S}, \mathrm{CO}_{2}$ dan lain-lain dengan jenis dan jumlahnya yang bervariasi sesuai dengan sumber gas alam.

Pada proses pembakaran, sebuah bahan bakar dan udara bercampur dan terbakar dapat dilakukan baik menggunakan mode nyala api maupun tanpa menggunakan mode nyala api. definisi api sendiri adalah suatu proses oksidasi dari pembakaran kimiawi yang memiliki panas dan cahaya. Warna api dipengaruhi oleh 2 hal yaitu kandungan bahan bakar dan campuran udara yang ikut terbakar. Ketika api memiliki warna cenderung merah hal tersebut dapat diartikan bahwa bahan terbakar api tersebut memiliki nilai kalor yang relatif rendah, atau udara yang mencampuri proses pembakaran hanya sedikit sehingga campuran kaya. Saat api berwarna kebiruan adalah sebaliknya yang merepresentasikan nilai kalor bahan bakar yang tinggi atau campuran miskin. Terdapat dua tipe mode nyala api, yaitu premixed flame dan diffusion flame.

\section{METODE PENELITIAN}

Dengan metode eksperimental yang digunakan untuk mengetahui nyala warna api dan tinggi api dengan variasi debit aliran debit aliran $0,204 \mathrm{~m}^{3} / \mathrm{jam}$, $0,245 \mathrm{~m}^{3} / \mathrm{jam}, 0,285 \mathrm{~m}^{3} / \mathrm{jam}, 0,326 \mathrm{~m}^{3} / \mathrm{jam}, 0,367$ $\mathrm{m}^{3} / \mathrm{jam}$.



Gambar 1 Skema Penelitian 
Keterangan :

1. Tabung LPG atau 6. Alas dudukan $\mathrm{CNG}$

kamera

2. Katub/Valve

7. Kamera DSLR

3. Anemometer

8. Selang

4. Background hitam

9. PC

5. Bunsen burner

Proses pertama yaitu mempersiapkan bahan dan alat yang digunakan untuk penelitian tinggi dan warna api LPG dan CNG. Selanjutnya debit aliran divariasikan sebesar $0,204 \mathrm{~m}^{3} / \mathrm{jam}, 0,245 \mathrm{~m}^{3} / \mathrm{jam}$, 0,285 $\mathrm{m}^{3} / \mathrm{jam}, 0,326 \mathrm{~m}^{3} / \mathrm{jam}, 0,367 \mathrm{~m}^{3} / \mathrm{jam}$.

Untuk pengambilan data tinggi dan warna api dilakukan dengan merekam menggunakan kamera Nikon D3200 yang dan diolah dengan software imageJ yang selanjutnya hasil ditulis secara manual.

Tahap Akhir Penelitian yaitu mematikan api pada bunsen burner, membersihkan alat.

\section{HASIL DAN PEMBAHASAN}

A. Analisa Tinggi Api

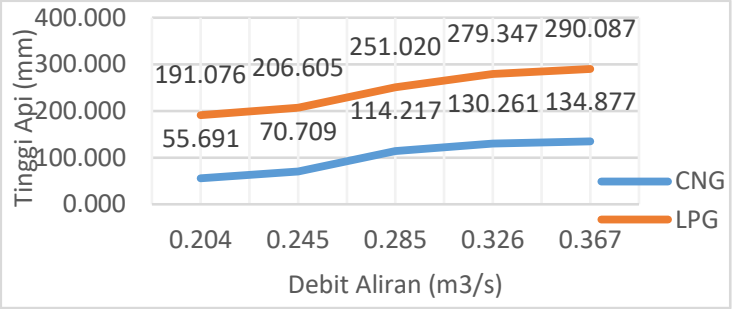

Gambar 2 Grafik Tinggi Nyala Api CNG dan LPG Terhadap Debit Aliran

Pada Gambar 2 terlihat bahwa terjadi peningkatan tinggi nyala api pada variasi debit aliran Meningkatnya tinggi nyala api karena debit aliran bahan bakar gas yang mengalir terus menerus mengakibatkan gas mampu bakar keluar semakin banyak dan menghasilkan api menyala semakin tinggi . Tinggi nyala api pada debit aliran 0,204 m3/jam adalah 55,691 mm untuk CNG dan 191,076 mm untuk LPG. Seiring dengan penambahan debit aliran bahan bakar gas, nyala api mengalami perubahan ketinggian, pada debit aliran 0,367 m3/jam yaitu $134,877 \mathrm{~mm}$ untuk CNG dan 290,087 mm untuk LPG.

Nyala api tertinggi CNG dan LPG ada pada debit aliran tertinggi yaitu $0,367 \mathrm{~m} 3 /$ jam dan nyala api terendah ada pada suplai udara terendah sebesar 0,204 m3/jam. Dapat disimpulkan semakin tinggi debit aliran bahan bakar, semakin tinggi pula nyala api yang dihasilkan. Hasil ini sama dengan penelilti sebelumnya yang mengatakan perubahan AFR terhadap karakteristik api pembakaran premixed minyak kapuk pada burner memberikan geometri api yang semakin membesar (dengan tinggi api 1,34 cm pada AFR 0,143:1 hingga tinggi api 4,429 $\mathrm{cm}$ pada AFR 1,526:1.

\section{B. Analisa Warna Api}

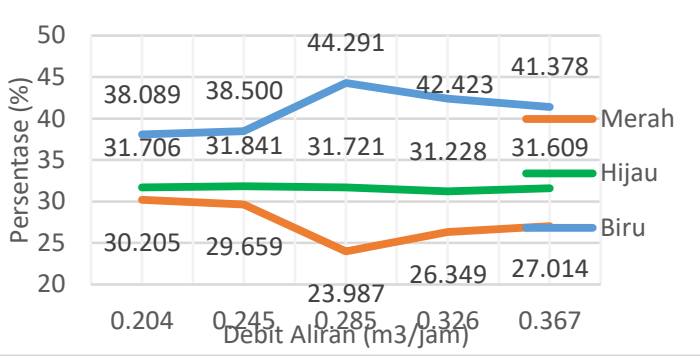

Gambar 3 Persentase Warna Api Merah, Hijau dan

Biru CNG Terhadap Variasi Debit Aliran

Dari Gambar 3 bahwa bahan bakar CNG semakin tinggi laju debit aliran bahan bakar semakin tinggi pula persentase warna api biru,namun turun secara perlahan, sebaliknya semakin tinggi laju debit aliran bahan bakar semakin rendah pula persentase warna api merahnya. Dapat dilihat dari grafik diatas, persentase warna api biru terjadi peningkatan pada debit aliran $0,285 \mathrm{~m}^{3} / \mathrm{jam}$, dan pada variasi suplai ini merupakan nyala api biru terbaik. Hal ini disebabkan oleh campuran udara dan bahan bakar ideal sehingga penambahan didebit selanjutnya campuran menjadi kaya dan mengalami penurunan dengan persentase $41,378 \%$. sebaliknya berbanding terbalik dengan warna api merah.

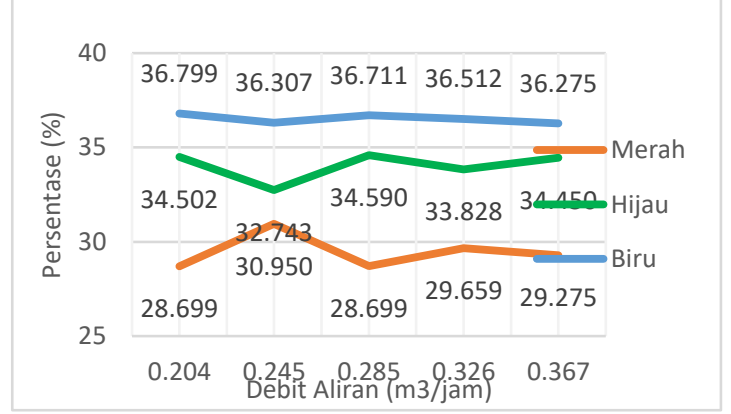

Gambar 4 Persentase Warna Api Merah, Hijau dan

Biru LPG Terhadap Variasi Debit Aliran

Dari Gambar 4 bahwa bahan bakar LPG semakin tinggi laju debit aliran bahan bakar semakin turun persentase warna api biru,namun turun secara perlahan, semakin tinggi laju debit aliran bahan bakar nyala warna api hijau dan merah terjadi fluktuatif saling berbanding terbalik. Persentase nyala api warna biru teringgi berada pada debit aliran 0,204 $\mathrm{m}^{3} / \mathrm{jam}$ yaitu $36,799 \%$ dan terus menurun pada aliran debit $0,367 \mathrm{~m}^{3} / \mathrm{jam}$ dengan persentase $36,275 \%$. Dapat dilihat dari grafik diatas, persentase warna api 
biru terjadi peningkatan pada debit aliran 0,285 $\mathrm{m}^{3} / \mathrm{jam}$. Hal ini disebabkan oleh semakin bertamtambahnya debit aliran bahan bakar, perbandingan udara dan bahan bakar semakin kaya sehingga mengalami penurunan.

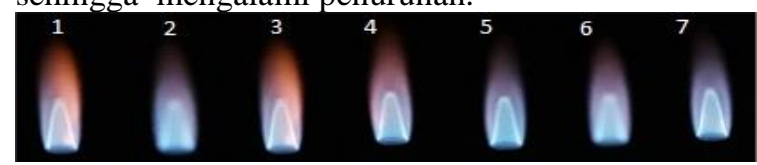

Gambar 5 Visualisasi Nyala Api CNG

\section{KESIMPULAN DAN SARAN}

Nyala api tertingg CNG dan LPG ada pada debit aliran bahan bakar tertinggi yaitu $0,367 \mathrm{~m}^{3} / \mathrm{jam}$ dan nyala api terendah ada pada debit aliran bahan bakar terendah sebesar $0,204 \mathrm{~m}^{3} / \mathrm{jam}$. Namun tinggi nyala api tertinggi pada $\mathrm{CNG}$ lebih rendah dari pada nyala api terendah LPG. Hal ini disebabkan karena perbedaan senyawa mampu bakar dari penyusun CNG dan LPG. Persentase warna api biru CNG ratarata tertinggi pada debit aliran $0,285 \mathrm{~m}^{3} / \mathrm{jam}$ sebesar 44,291\% dan LPG pada debit aliran $0,204 \mathrm{~m}^{3} / \mathrm{jam}$ sebesar 36,779\%. Pada suplai 0,245 $\mathrm{m}^{3} / \mathrm{jam} \mathrm{CNG}$ merupakan nyala api hijau terbaik sebesar 31,841 $\%$ dan untuk LPG pada debit aliran $0,285 \mathrm{~m}^{3} / \mathrm{jam}$ dengan nilai $34,59 \%$. Persentase warna api merah terbesar berada pada debit aliran 0,204 $\mathrm{m}^{3} / \mathrm{jam}$ sebesar 30,205 \% dan LPG pada debit aliran 0,245 $\mathrm{m}^{3} /$ jam sebesar $30,95 \%$, hal tersebut dikarenakan perbedaan senyawa kedua bahan bakar dan perbedaan Air Fuel Ratio. CNG membutuhkan campuran bahan bakar yang lebih kaya untuk biasa setara dengan LPG.

Sebaiknya dalam proses penyalaan api dilakukan secepat mungkin ketika gas mulai keluar. Dan penyalaan api sebaiknya dilakukan pada debit aliran rendah kemudian setelah api menyala dapat dilakukan penambahan debit aliran secara perlahan.

\section{DAFTAR PUSTAKA}

Farid. M. B. 2007. "Pendeteksi dan pengaman kebocoran gas LPG (Butana) Berbasis Mikrokontroller melalui sms sebagai media informasi". Pens- Surabaya.

Fawas B. H. 2018. "analisa karakteristik pembakaran premix biogas dengan liquefied petroleum gas (LPG) menggunakan Bunsen burner". Jember: Fakultas Teknik, Universitas Jember.

Firmansah. Yulianto. 2017. "Analisis Kekuatan Tangki CNG Ditinjau Dengan Material Logam Lapis Komposit Pada Kapal Pengangkut Compressed Natural Gas". Surabaya : Fakultas Teknologi Kelautan, Institut Teknologi Sepuluh Nopember (ITS).
Firmansyah R. 2018. "Penelitian Kestabilan Dan Panjang Nyala Api Premix Akibat Variasi Diameter Dalam Ring Menggunakan Gas Propane Pada Bunsen Burner". Universitas Indonesia.

Glassman. I. 1977. "Combustion (3rd ed)". New York: Academic Press.

Grover. V. 2015. "Model Lesson On Parts Flame". DAV Collage Of Education, Abohar.

Lembaga Ilmu Pengetahuan Indonesia. 2011. Kajian Teknis Konversi BBM ke BBG untuk Kendaraan.

Nurkoyim Kustanto, 2014. "Perilaku Rambat Api Pada Pembakaran Etanol Yang Dikayakan Dengan LPG" Jember: Fakultas Teknik, Universitas Jember.

Pranoto, B. 2012. "Pengaruh Variasi Air Fuel Ratio (AFR) Terhadap Karakteristik Api Pembakaran Premixed Minyak Kapuk Pada Burner" Teknik Mesin, Fakultas Teknik, Universitas Brawijaya.

Rosadi. 2017. "Analisis Karakteristik Thermal Api Syn-Gas Pada Gasifikasi Biomassa Tipe Downdraft Dengan Oksidator Udara". Jember: Fakultas Teknik, Universitas Jember.

Sasongkoa. Wijayanti. 2015. "Karakteristik Api Premiks Biogas pada Counterflow Burne". Banjarmasin: Proceeding Seminar Nasional Tahunan Teknik Mesin XIV (SNTTMXIV).

Soetadi dan Kawano. 2012. "Studi Eksperimen Distribusi Temperatur Nyala Api Kompor Bioetanol Tipe Side Burner dengan Variasi Diameter Firewall". Teknik Mesin, Fakultas Teknologi Industri, Institut Teknologi Sepuluh Nopember (ITS).

Turns. S. R. 1996. "An Introduction To Combustion Concepts And Application”. Mc Graw Hill.

Widarto. Z. 2007. "Pendeteksi dan pengaman kebocoran gas LPG (Butana) Berbasis Mikrokontroller melalui sms sebagai media informasi". Pens- Surabaya.

Yonathan. 2008. "Pengaruh Variasi Temperature Bahan Bakar Gas Lpg Campuran Terhadap Karakteristik Nyala Api Difusi Pada Burner Gas Tipe Ejected Combustor". Depok : Fakultas Teknik, Universitas Indonesia. 